\title{
Effects of Alzheimer's Disease on Different Cortical Layers: The Role of Intrinsic Differences in A $\beta$ Susceptibility
}

\author{
Rita R. Romito-DiGiacomo, ${ }^{1}$ Harry Menegay, ${ }^{3}$ Samantha A. Cicero, ${ }^{2}$ and Karl Herrup ${ }^{1}$ \\ ${ }^{1}$ Department of Neuroscience, Alzheimer Research Laboratory, and ${ }^{2}$ Department of Pharmacology, Case School of Medicine, Cleveland, Ohio 44106, and \\ ${ }^{3}$ University Memory and Aging Center, Fairhill Center, Cleveland, Ohio 44120
}

\begin{abstract}
Alzheimer's disease is late life dementia associated with significant neurodegeneration in both cortical and subcortical regions. During the $\sim 10$ year course of the disease, neurons are lost in a progressive pattern that is relatively consistent among individuals. One example of this is the progression of disease pathology found in both the neocortex and archicortex. In these structures, the earliest problems can be found in superficial cortical layers (II-IV), whereas later the disease advances to involve the deeper cortical layers (V-VI). It is unclear whether these apparent differences in sensitivity are intrinsic to the neurons or imposed by external factors such as the pattern of connections. We used $\beta$-amyloid $(\mathrm{A} \beta)$ peptide treatment of cultured mouse neurons as our model system. We show first that, as in hippocampus, dissociated cultures of embryonic cortical neurons are biased toward the survival of cells that were finishing division in the ventricular zone at the time of harvest. Thus, embryonic day 13.5 (E13.5) cultures contain primarily deep-layer neurons whereas E16.5 cultures contain cells destined for upper layers. We use this cell-type specific segregation to our advantage and show, using both differences in gene expression profiles and $\mathrm{A} \beta$ survival curves, that deeper layer neurons are significantly more resistant to the toxic effects of $\mathrm{A} \beta$ than are cells from the more superficial strata. This suggests that an intrinsic underlying biology drives at least part of the $\mathrm{AD}$ progression pattern and that the time of harvest is a crucial variable in the interpretation of any cortical culture experiment.
\end{abstract}

Key words: expression array; cell culture; rodent; neocortex; $\mathrm{A} \beta$ peptide; neuronal death

\section{Introduction}

Alzheimer's disease (AD) is the most common dementia of late life. Accompanying the neurological signs is a multidimensional pathology involving abnormal deposits of $\beta$-amyloid (A $\beta$ ) peptides, hyperphosphorylated tau, atrophy of neurites and a progressive loss of synapses, and, ultimately, loss of neuronal cell bodies. Limbic structures are heavily affected (amygdala, entorhinal cortex, and hippocampus), but all regions of the brain seem to register some level of degenerative change.

From the standpoint of understanding disease mechanism, it is intriguing that the progression of the disease is not uniform. Limbic regions, in particular the perihippocampal formation, are affected first. Even within a single region, there appears to be a regional progression. Detailed quantitative studies are not numerous, but the disease appears to involve the more superficial layers of the cortex (layer II) and, to a lesser extent, layer IV, before progressing to involve all layers (Hyman et al., 1984; Gomez-Isla et al., 1996). Human pathological studies are by their nature descriptive, but this pattern of progression raises the mechanistic question of whether the pattern is an intrinsic prop-

Received 0ct. 4, 2006; revised June 20, 2007; accepted June 20, 2007.

This work was supported by the National Institutes of Health Grant NS20591 and a major gift from Coins for Alzheimer's Research Trust. Funds were also obtained from the Blanchette Hooker Rockefeller Fund. We thank Drs. Randall York and Jianmin Chen for helpful discussions during the preparation of this manuscript.

Correspondence should be addressed to Karl Herrup at the above address. E-mail: herrup@biology.rutgers.edu.

S. A. Cicero's present address: St. Jude Children's Research Hospital, Department of Developmental Neurobiology,

332 North Lauderdale, Danny Thomas Research Center D2031, Memphis, TN 38105.

DOI:10.1523/JNEUROSCI.1008-07.2007

Copyright $\odot 2007$ Society for Neuroscience $\quad$ 0270-6474/07/278496-09\$15.00/0 erty of the neurons themselves or one imposed on the affected neurons by virtue of their afferent or efferent connections. We sought to address this question in cell culture.

The neurons of the mammalian cerebral cortex are generated in a complex pattern of migration and settling with layers $\mathrm{V}$ and VI generated early [embryonic day 13 (E13) and E14 in mouse] and layers II and III are generated later ( E16) (Takahashi et al., $1993,1995,1999)$. Tangential migrants from the ganglionic eminence that give rise to the GABAergic neurons are mostly, but not completely present by E16 as well (Anderson et al., 1999; Lavdas et al., 1999). Taking advantage of this invariant sequence, we began a series of experiments aimed at determining the differential responsiveness of neocortical cells to the degenerative processes induced by the toxic effects of the $\mathrm{A} \beta$ peptide, a major pathogenic agent in AD. We reasoned that, if we compared cultures harvested on E13 with those harvested on E16, we could compare the responses of deep-layer cells (E13 harvest) with the total population of the cortex (E16 harvest), allowing us to determine whether the differential sensitivity of the different cortical layers (Gomez-Isla et al., 1996) was apparent in our tissue-culture model.

We report here that there is a clear intrinsic difference in $\mathrm{A} \beta$ susceptibility between the deeper, more resistant layer V/VI neurons and superficial, more sensitive layer II/III neurons. In pursuit of these studies, we have relearned the 30-year-old lessons of Banker and Cowan (1977). Under standard conditions of dissociation and plating, the harvest of rodent cerebral cortical neurons is heavily biased toward recovery of cells that are just com- 


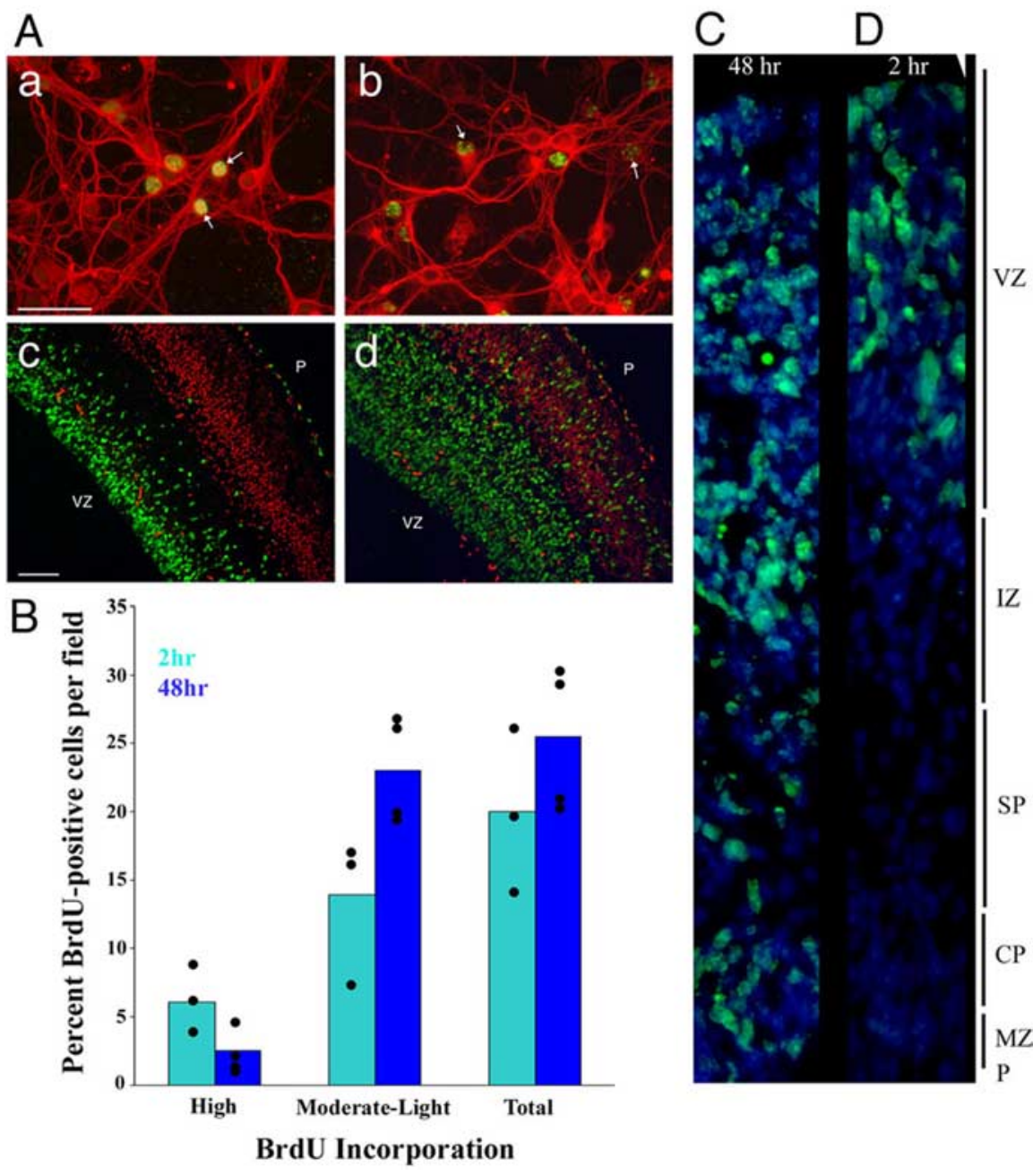

Figure 1. BrdU incorporation and quantification in E15.5 embryos. $A, E 15.5$ cortical cultures labeled with BrdU for $2 \mathrm{~h}(\boldsymbol{a})$ or $48 \mathrm{~h}$ (b) before being killed. Cultures were stained with TuJ1 (red) and BrdU (green). Corresponding sections were also stained with BrdU (green) and Tbr-1 (red) and show BrdU incorporation restricted to the ventricular zone in the $2 \mathrm{~h}$ injected cortex (c) whereas the $48 \mathrm{~h}$ injection shows labeled cells throughout the cortex (d). B, Summary of the quantification of BrdU incorporation in E15.5 cultures killed either 2 or $48 \mathrm{~h}$ after injection. Cultures were stained with BrdU and TuJ1 and counts were done on double-positive cells. The graph shows more intensely stained cells in the $2 \mathrm{~h}$ injected cultures and more diffusely stained cells in the $48 \mathrm{~h}$ injected cultures. Despite the expected difference in intensity, the relative number of total BrdU positive cells is very similar, consistent with the belief that only cells in the ventricular zone survive culturing. $C, D$, The in vivo staining pattern further confirms this belief showing a large number of BrdU-positive cells throughout the cortex of a E13/15 ( $(C)$ embryo when compared with an E15.5 embryo injected with BrdU $2 \mathrm{~h}$ earlier $\left(\mathrm{E} 15^{+2} ; \boldsymbol{D}\right)$. We would expect the counts in $\boldsymbol{B}$ to reflect this difference if all cortical layers survived culturing. Scale bars: (in $\boldsymbol{A a}) \boldsymbol{A a}, \boldsymbol{A b}, 50 \mu \mathrm{m}$; (in $\boldsymbol{A c}) \boldsymbol{A c}, \boldsymbol{A d}, 100 \mu \mathrm{m}$. VZ, Ventricular zone; IZ, intermediate zone; SP, subplate; $C P$, cortical plate; $M Z$, marginal zone; $P$, pia.

pleting neurogenesis. The findings offer new strategies for approaching the analysis of cortical neuron behavior and also suggest caution in the interpretation of the existing literature on $\mathrm{A} \beta$ responsiveness of cortical cultures.

\section{Materials and Methods}

Animals. Timed pregnancies were obtained by mating pairs of wild-type C57BL/6J mice and checking for the presence of a vaginal plug daily. The plug date was designated E0.5 and all ages were calculated from this date. Plugged females were killed by cervical dislocation and embryos were harvested between E13.5 and E17.5 and processed for sectioning (see below), or the cortices were isolated and their cells dissociated and cultured. For BrdU injections, pregnant dams were injected with BrdU (100 $\mu \mathrm{g} / \mathrm{g}$ weight) either 2 or $48 \mathrm{~h}$ before being killed. The Case Western Reserve University Animal Resource Center is a fully accredited Association for Assessment and Accreditation of Laboratory Animal Care facility. All activities were in accord with the appropriate guidelines and the
University Institutional Animal Care and Use Committee considered and approved all procedures.

Cortical cultures. Pregnant dams were killed by cervical dislocation and embryos were dissected from the uterine horns on ice-cold PBS/ glucose $(1 \mathrm{mg} / \mathrm{ml})$ as described previously (Cicero and Herrup, 2005). Briefly, brains were dissected and cortices removed and collected in ice-cold PBS/glucose. The cortices were then stripped of the meninges, minced, and trypsinized at $37^{\circ} \mathrm{C}$ for $10-15 \mathrm{~min}$. The tissue was then transferred to a conical tube containing DMEM plus 10\% FCS to inactivate the tryp$\sin$. The tissue was then transferred to a conical tube containing Neurobasal media supplemented with B-27, penicillin/streptomycin, and $2 \mathrm{~mm}$ L-glutamine (Invitrogen, Carlsbad, CA). Tissue was then triturated and live cell number was determined by staining with Trypan blue. Cells were then plated at a density of 50,000 cells/well in 24-well plates containing poly-L-lysine $(0.05 \mathrm{mg} / \mathrm{ml}$; P-4707; Sigma, St. Louis, MO)-coated glass coverslips, or at a density of 2.6 million cells for $100 \mathrm{~mm}$ poly-Llysine-coated plates. Cells were then incubated for a period of $4-7 \mathrm{~d}$ in vitro (DIV) in Neurobasal medium. Cultures to be treated with amyloid- $\beta$ peptide were first grown undisturbed for $5 \mathrm{~d}$ and then treated. The $\mathrm{A} \beta$ peptide was purchased from American Peptide (Sunnyvale, CA) as a dry powder and resuspended to a concentration of $2 \mathrm{~mm}$ using sterile water. The $\mathrm{A} \beta$ solution was allowed to sit at room temperature for $\sim 1 \mathrm{~h}$ before vortexing aliquoting and freezing at $-20^{\circ} \mathrm{C}$. Individual aliquots were fibrillized by incubating them at $37^{\circ} \mathrm{C} 5 \mathrm{~d}$ before use; any remaining fibrillized $\mathrm{A} \beta$ was stored at $4^{\circ} \mathrm{C}$.

Cell counts. Cell death in response to $\mathrm{A} \beta_{1-42}$ treatment was determined in E13.5-E17.5 cultures grown for 5 DIV. Briefly, cultures were treated with $\mathrm{A} \beta_{1-42}$ at concentrations of $0,0.3$, $1,3,10$, and $30 \mu \mathrm{M}$ for $72 \mathrm{~h}$. After treatment, cells were stained using the Live/Dead Viability/ Cytotoxicity kit from Invitrogen and cell loss was determined by counts. Each age of culture was repeated on three separate experiments; in each experiment, nine fields were counted in each of three wells for each treatment concentration (27 total fields/treatment/experiment) at $40 \times$ magnification. Total cell numbers were combined and averaged to generate a response curve for all ages tested. Percent loss was calculated from untreated controls. For T-box protein (Tbr-1) survival, E13.5 and E16.5 cultures were treated with $\mathrm{A} \beta_{1-42}$ for $72 \mathrm{~h}$. Cells were then stained with Tbr-1 and $\beta$-III tubulin (TuJ1) antibodies by immunohistochemistry, and double-positive cells were counted under fluorescent optics using the same sampling procedure described above. BrdU counts were done on E15.5 cultures established from embryos whose dams had been injected with BrdU 2 or $48 \mathrm{~h}$ before culturing. The cultures were then grown for $5 \mathrm{~d}$ followed by staining with antibodies against $\mathrm{BrdU}$ and $\mathrm{TuJ} 1$ and double-positive cells were counted. Each experiment was done in triplicate with nine fields counted in each well and each age was repeated three times.

RNA isolation and expression arrays. E13.5 and E16.5 cultures were grown on poly-L-lysine-coated $100 \mathrm{~mm}$ plates for $5 \mathrm{DIV}$ and then treated with $10 \mu \mathrm{M} \mathrm{A} \beta_{1-42}$. Cultures were then harvested at 0,5 , and $17 \mathrm{~h}(10$ plates each) after treatment. After harvest, the plates were chilled on ice and rinsed with DEPC-treated PBS. Cells were then scraped and RNA 
was extracted using the Qiagen (Hilden, Germany) RNeasy Midi kit (catalog \#75142). The quality of the extracted RNA was determined by agarose gel electrophoresis followed by staining with ethidium bromide and visualization of the $18 \mathrm{~S}$ and $28 \mathrm{~S}$ RNA bands by UV light. This experiment was done in triplicate. The resulting RNA was analyzed by the Gene Expression Array Core Facility at Case Western Reserve University using whole-genome Affymetrix (Santa Clara, CA) gene expression arrays. The quality and quantification of the RNA was checked again using a Nanodrop spectrophotometer, cleaned on a Qiagen RNeasy column, and then requantified and evaluated on an Agilent (Palo Alto, CA) Bioanalyzer. The total RNA was then used to generate first-strand cDNA by reverse transcription using a T7-linked oligo(dT) primer and Superscript reverse transcriptase. Second-strand cDNA synthesis was generated by using the T7 MEGAscript kit from Ambion (Austin, TX). The biotinylated probes were then hybridized to an Affymetrix Genechip Mouse Genome 4302.0 array, and scanned with an Affymetrix gene-chip scanner.

Expression analysis was performed with Affymetrix MicroArray Suite 5.0, Silicon Genetics (Redwood City, CA) GeneSpring 7.2, Microsoft (Redmond, WA) Excel XP, BAMarray 2.0, and GenMAPP (Gene MicroArray Pathway Profiler) 2.0 software. Affymetrix MAS was used to convert the signal log ratio to fold-change for the data. The expression data were then filtered using Microsoft Excel. Probes that were not determined to be "present" or "marginal" by MAS on gene chips of at least two of the three replicate samples were not analyzed further. The data were normalized using the median of each gene on each gene chip. Cluster analysis was done on probe sets with a $p$ value $<0.05$ and a more than twofold change in level of expression using GeneSpring. To find genes with statistically significant changes that might be hidden in spurious noise in the ANOVA analysis in GeneSpring, the array data were processed by BAMarray. GenMAPP 2.0 was used to identify biological pathways or functionally grouped genes that were up or downregulated across time points or day of harvest.

Histology and immunocytochemistry. Pregnant dams were killed and their gravid uteri removed and stored on ice. After individual removal from the uterus, the embryonic brains were removed and immersionfixed in $4 \%$ paraformaldehyde/PBS overnight at $4^{\circ} \mathrm{C}$ followed by equilibration in 30\% sucrose in PBS. After this, they were embedded in OCT and sectioned on a cryostat at $10 \mu \mathrm{m}$ and collected on Fisherbrand Plus slides. Sections were stained as described previously (Cicero and Herrup, 2005). Briefly, sections or 24-well plates were treated with citrate buffer for $10 \mathrm{~min}$ at $95^{\circ} \mathrm{C}$ and then cooled to room temperature. Slides were then rinsed three times in PBS and blocked in $10 \%$ normal goat serum in PBS containing $0.1 \%$ Tween for $45 \mathrm{~min}$ at room temperature (RT). The slides were then incubated in one of the following primary antibodies diluted in blocking solution: rat anti-BrdU (1:100) from Abcam (Cambridge, MA), rabbit anti-Tbr-1 (1:1000), a generous gift from Dr. Robert Hevner (University of Washington, Seattle, WA), or mouse anti-Tuj1 (Covance, Cumberland, VA). Slides were then rinsed in PBS three times for $12 \mathrm{~min}$ followed by incubation in one of the following secondary antibodies diluted in blocking solution: goat anti-rat, goat anti-mouse, or goat anti-rabbit conjugated with Alexa 488 from Invitrogen (1:1000) or Cy-3 (1:500) from Jackson ImmunoResearch (West Grove, PA). Slides were incubated in secondary antibody for $2 \mathrm{~h}$ at RT followed by washing
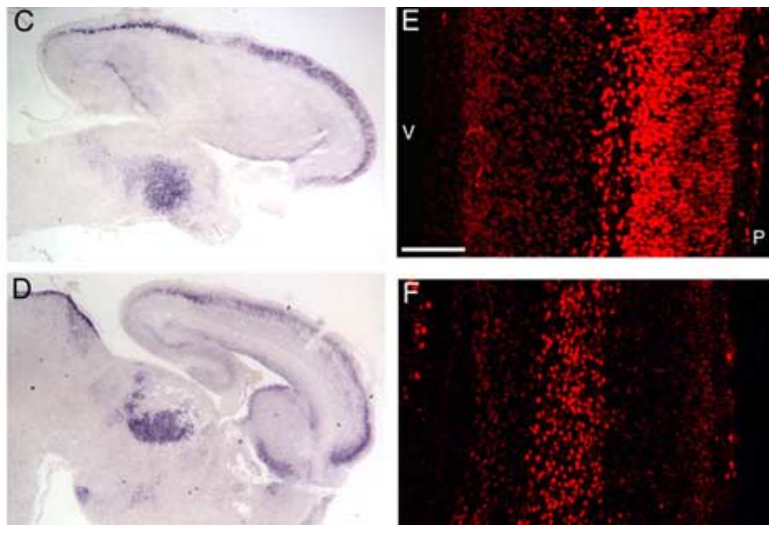

Figure 2. Layer-specific expression patterns in vivo. $\boldsymbol{A}, \boldsymbol{B}$, Tbr-1 expression pattern is as shown by in situ hybridization in $\mathrm{E} 16(\boldsymbol{A})$

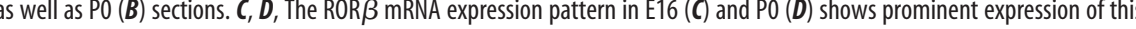
nuclear receptor gene in presumptive layer IV neurons. $\boldsymbol{E}, \boldsymbol{F}$, The Tbr-1 expression pattern in both ages is further confirmed by
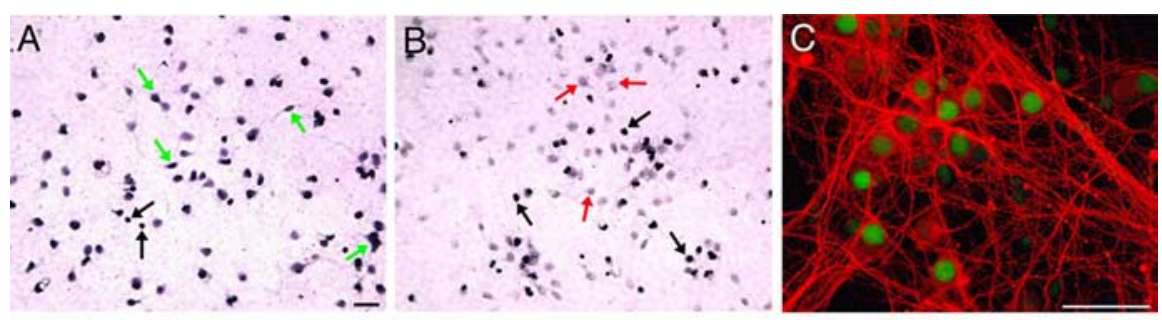

Figure 3. Layer-specific Tbr-1 expression pattern in vitro. $\boldsymbol{A}, \boldsymbol{B}, \boldsymbol{D}, \boldsymbol{E}$, In situ hybridization on $\mathrm{E} 13.5$ and $\mathrm{E} 16.5$ cultures showing of unknown identity. $\boldsymbol{C}, \boldsymbol{F}$, Immunocytochemistry of E13.5 (C) and E16.5 (F) cortical cultures shows TuJ1 (red) and Tbr-1 (green) staining. Scale bar: (in $\boldsymbol{C}) \boldsymbol{A}-\boldsymbol{F}, 50 \mu \mathrm{m}$.

three times for $12 \mathrm{~min}$ with PBS. If double labeling was done, slides were then blocked for $20 \mathrm{~min}$ and the above steps were repeated with the second set of primary and secondary antibodies. When needed, slides were also stained with DAPI (4,6,diamidino-2-phenylindole), diluted $1: 3000$ (from a $1 \mu \mathrm{g} / \mathrm{ml}$ stock), in the first of the final PBS wash steps.

Western blot analysis. E13.5 and E16.5 cultures were grown for 5 DIV followed by treatment with $10 \mu \mathrm{M} \mathrm{A} \beta_{1-42}$ for 10 min or $5 \mathrm{~h}$, in addition to untreated controls. Plates were then iced and cells were incubated in lysis buffer [containing (in mM): 20 Tris, $1 \%$ Triton X-100, $100 \mathrm{NaCl}, 40 \mathrm{NaF}$, 1 EDTA, 1 EGTA, $1 \mathrm{Na}_{3} \mathrm{VO}_{4}$, aprotinin, leupeptin, and PMSF] for 15 $\mathrm{min}$. Cells were then scraped and centrifuged at 13,000 rpm for $15 \mathrm{~min}$ at $4^{\circ} \mathrm{C}$. The supernatant was collected and the protein concentration was determined by the Bradford method. Equal amounts of protein $(20 \mu \mathrm{g})$ in Laemmli buffer were first boiled for $7 \mathrm{~min}$, then run on SDS-PAGE gels. Gels were then transferred onto polyvinylidene difluoride membranes as described previously (Combs et al., 2001). The blots were then incubated in monoclonal 4G10 antibody (1:1000; Upstate Biotechnology, Lake Placid, NY) or rabbit anti-Erk1/2 (1:1000; Santa Cruz Biotechnology, Santa Cruz, CA). Secondary antibodies used were HRPconjugated sheep anti-mouse (1:1000; GE Healthcare Bio-Sciences, Piscataway, NJ) or HRP-conjugated donkey anti-rabbit (1:1000; GE Healthcare Bio-Sciences). Blots were then developed using an enhanced 


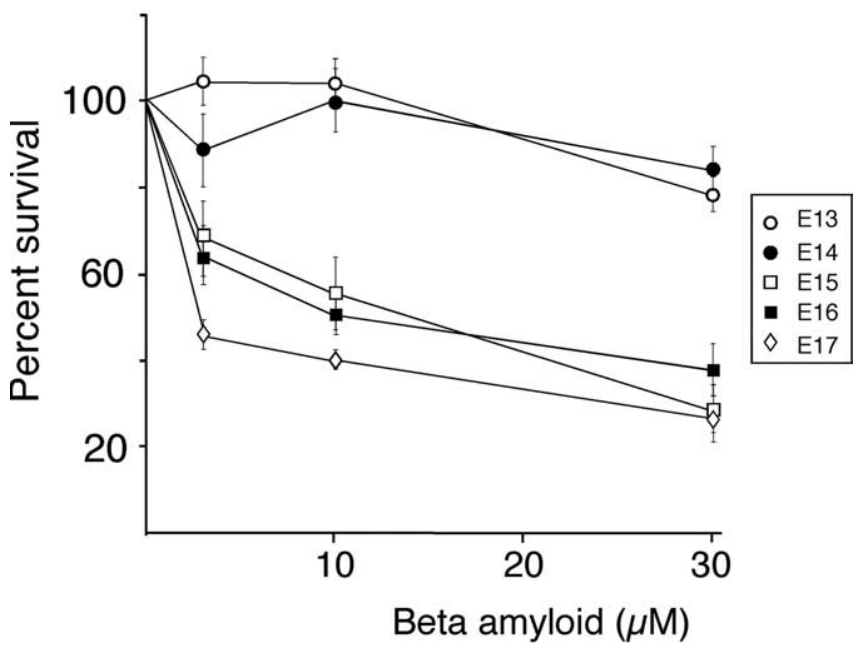

Figure 4. Cell survival of layer-specific cultures after $A \beta$ treatment. Cultures were treated for a period of $72 \mathrm{~h}$ with $A \beta_{1-42}$ then stained using a Live/Dead Viability/Cytotoxicity kit followed by cells counts. The values are expressed as the percentage of cells remaining relative to untreated sister cultures. The survival curves for cells harvested at different ages (see legend) are significantly different. Error bars indicate SEM.

chemiluminescence system (GE Healthcare Bio-Sciences) following the manufacturer's instructions.

In situ hybridization. Probes were generated as follows: PCR primers were flanked with NotI (forward primer) and HindIII (reverse primer) restriction enzyme sequences to allow the PCR product to be cloned into pBluescript. A $731 \mathrm{bp}$ fragment was generated for Tbr-1 (forward, 5'AAGGAAAAAAGCGGCCGCCACTCGCTCTTTCACTTG-3'; reverse, 5' -CCCAAGCTTCAGGGCACACAGTGGTTA-3'); and a 377 bp fragment for retinoid orphan receptor $\beta(\operatorname{ROR} \beta)$ (forward, $A A G$ GAAAAAAGCGGCCGCCTGCAACATGTGATTCAG-3'; reverse, $5^{\prime}$ CCCAAGCTTCCCACTCAGGTGCATATT-3'). Fragments were then cloned into pBluescript and linearized for T7 transcription (antisense) using the Stratagene (La Jolla, CA) RNA transcription kit. After transcription, the product was precipitated using yeast tRNA and the pellet was then rinsed in $70 \%$ ethanol and resuspended in $50-75 \mu$ l of DEPC water. A small amount of the transcription product was run on an agarose gel to confirm probe size and estimate concentration.

Primary cortical cultures were grown for a period of $4-5 \mathrm{~d}$ then fixed with $4 \%$ paraformaldehyde/PBS for $2 \mathrm{~h}$ at $4^{\circ} \mathrm{C}$. For cryostat sections, the slides were fixed for $10 \mathrm{~min}$ at RT. Slides and cultures were then rinsed three times for $5 \mathrm{~min}$ in PBS followed by acetylation for $10 \mathrm{~min}$ at RT. Slides/cells were then rinsed three times for $5 \mathrm{~min}$ in PBS before incubating in hybridization solution for a minimum of $2 \mathrm{~h}$ at RT. Digoxygenin labeled probe was then diluted 1:100 or 1:200 in the hybridization solution and added to the slides/cells, and incubated overnight at $72^{\circ} \mathrm{C}$ in a humid chamber. In the case of cells grown in 24-well plates, PBS was added to the spaces between wells and the plate was wrapped in foil to create a humid chamber. Slides/cells were then rinsed in $5 \times \mathrm{SSC}$ at $72^{\circ} \mathrm{C}$ for $5 \mathrm{~min}$ followed by $0.2 \times$ SSC at $72^{\circ} \mathrm{C}$ for $1-3 \mathrm{~h}$. Slides/cells were then rinsed with $0.2 \times$ SSC for $5 \mathrm{~min}$ at RT before incubating in B1 $(0.1 \mathrm{M}$ Tris, $\mathrm{pH} 7.5,0.15 \mathrm{M} \mathrm{NaCl}$ ) solution for $5 \mathrm{~min}$ at RT. Slides/cells were then blocked in B1 solution containing 10\% heat inactivated goat serum for at least $1 \mathrm{~h}$ at RT. Anti-digoxygenin-alkaline phosphatase conjugated antibody from Roche was diluted 1:2500 in blocking solution and added to slides/cells overnight at $4^{\circ} \mathrm{C}$. Slides/cells were then rinsed three times for $5 \mathrm{~min}$ in B1 followed by equilibration in B2 (0.1 м Tris, $\mathrm{pH} 9.5,0.1 \mathrm{M}$ $\mathrm{NaCl}$, $50 \mathrm{~mm} \mathrm{MgCl} 2$ ) for 5-10 min. Slides/cells were then developed in B2 solution containing neuronal bungarotoxin/5-bromo-4-chloro-3indolyl phosphate and levamisole $(0.5 \mathrm{mg} / \mathrm{ml})$ in the dark for $1 \mathrm{~h}$ to overnight. Slides/cells were then rinsed in PBS. Cells were stored in PBS while slides were dehydrated and mounted in Permount.

\section{Results}

\section{Layer-specific neuronal cultures}

The work of Banker and Cowan (1977) has shown that the day of harvest biases the composition of the resulting cultures significantly. The work led to the conclusion that cultured hippocampal neurons harvested during neurogenesis were most likely to contain cells that were in the process of finishing their final cell division. Were this true for the cerebral cortex as well as hippocampus, it would greatly aid in our analysis of the effects of $A \beta$ by allowing us to enrich our cultures with cells destined for different cortical layers in a controlled manner. Before treating our cultures with $\mathrm{A} \beta$ peptide, therefore, we wished to verify the composition of our cultures. We chose both BrdU birthdating protocols as well as examination of the expression of different genes that show a layer-specific pattern in the rodent cerebral cortex.

The brains of the embryos were dissected and their neurons used for cortical nerve cell cultures as described in the Materials and Methods. Pregnant dams were injected on E13.5 with BrdU and their pups harvested $2 \mathrm{~h}$ later for isolation and plating of their cortical neurons (E13 ${ }^{+2}$ neurons). After 5 DIV, many of these neurons could be brightly labeled with BrdU antibody (Fig. $1 \mathrm{Aa}$, arrows). Similarly, many BrdU-positive cells were also found in E16 ${ }^{+2}$ cultures after 5 DIV (data not shown). If Banker and Cowan (1977) were correct, neurons isolated from embryos harvested on E15.5 after injection of the dams on E13.5 (E13/15 neurons) should be unlabeled because the BrdU should have been diluted below the level of detection. This is not the case, however, as shown in Figure $1 A b$. Rather, there are numerous cells with lightly labeled nuclei (arrows).

To clarify the situation, we turned to an analysis of sections. When BrdU is administered at E15.5 and embryos harvested $2 \mathrm{~h}$ later, the distribution of BrdU staining seen in Figure $1 A c$ is observed. A tight band of labeled nuclei (green) is seen in the ventricular zone with the rest of the cortical anlage mostly free of labeled cells. If embryos are injected $2 \mathrm{~d}$ earlier (E13.5), however, the BrdU staining pattern shown in Figure $1 \mathrm{Ad}$ is found. The ventricular zone still contains labeled neurons although the most brightly labeled cells have migrated into the intermediate zone and cortical plate. To determine how this situation translated to our cultures, we administered BrdU at E13.5 and harvested the E13/15 neurons. In parallel, we injected E15.5 pregnant dams and harvested the neurons $2 \mathrm{~h}$ later (E15 ${ }^{+2}$ neurons). The cortical neurons were cultured and grown for $5 \mathrm{~d}$, and then labeled with anti-BrdU and anti- $\beta$-III tubulin (TuJ1) antibodies. We found over twice as many brightly labeled BrdU/TuJ1-positive neurons in the $\mathrm{E} 15^{+2}$ cultures than in the E13/15 cultures ( $\sim 6$ vs $2.6 \%$ ); however, the total number of BrdU positive cells was similar: $19 \%$ in $\mathrm{E} 15^{+2}$ versus $25 \%$ in E13/15 (Fig. $1 B$ ). When we looked at sections from littermate embryos (Fig. $1 C$ ), we could see BrdU labeling throughout the cortex of the E13/15 brain, whereas the $\mathrm{E} 15^{+2}$ brain had labeling restricted to the ventricular zone (Fig. $1 D)$. Because the percentage of BrdU-labeled cells in the two culture preparations was similar, this supports the Banker and Cowan (1977) hypothesis that only the cells that are proliferating, or have just completed their final mitosis, survive culturing. If this were not the case, we would have expected to see a much higher percentage of BrdU-labeled cells in our E13/15 cultures.

We sought a means to independently validate the BrdU results using a variety of layer-specific neuronal markers. The T-box protein Tbr-1 is reported to be expressed in cortical layers $\mathrm{V}$ and VI (Bulfone et al., 1995; Rubenstein et al., 1999). As shown in Figure 2, the cells of the E16 cortical plate are positive for both 
Table 1. Named genes that are differentially expressed in E13.5 cultures after treatment with $A \boldsymbol{\beta}$ for $17 \mathrm{~h}$

\begin{tabular}{|c|c|c|c|}
\hline Probe set & GenBank accession number & Symbol & Gene name \\
\hline \multicolumn{4}{|c|}{ Named genes expressed significantly higher after $A \beta$ treatment } \\
\hline 1425719_a_at & BC002019.1 & Nmi & $\mathrm{N}$-myc (and signal transducer and activator of transcription) interactor \\
\hline 1415944_at & NM_011519.1 & Sdc1 & Syndecan 1 \\
\hline 1426215_at & AF071068.1 & Ddc & Dopa decarboxylase \\
\hline 1450677_at & NM_007691.1 & Chek1 & Checkpoint kinase 1 \\
\hline 1424086_at & ВС025514.1 & Oaf & Out at first \\
\hline 1415810_at & NM_010931.1 & Uhrf1 & Ubiquitin-like, containing Pumilio homology domain and RING finger domains, 1 \\
\hline 1424334_at & ВС010346.1 & Tspan17 & Tetraspanin 17 \\
\hline 1419669_at & U97073.1 & Prtn3 & Pre-pro-proteinase 3 \\
\hline 1417108_at & NM_029091.1 & Klc4 & Kinesin light chain 4 \\
\hline 1448825_at & NM_133667.1 & Pdk2 & Pyruvate dehydrogenase kinase, isoenzyme 2 \\
\hline 1418308_at & NM_008316.1 & Hus1 & Hus1 \\
\hline 1416763_at & NM_133837.1 & Cdc123 & Cell division cycle 123 \\
\hline 1421915_a_at & NM_009176.1 & St3gal3 & ST3 $\beta$-galactoside $\alpha$-2,3-sialyltransferase 3 \\
\hline 1448598_at & NM_011846.1 & Mmp17 & Matrix metalloproteinase 17 \\
\hline 1417001_a_at & NM_023665.1 & D4Wsu53e & Hypothetical protein LOC27981 \\
\hline 1428029_a_at & BC028539.1 & H2afv & $\mathrm{H} 2 \mathrm{~A}$ histone family, member $\mathrm{V}$ \\
\hline 1421048_a_at & NM_023249.1 & Ypel1 & Yippee-like 1 \\
\hline 1418467_at & NM_025891.1 & Smarcd3 & SWISNF-related matrix-associated actin-dependent regulator of chromatin, subfamily d, member 3 \\
\hline 1416492_at & NM_007633.1 & Cone1 & Cyclin E1 \\
\hline 1417635_at & NM_011449.1 & Spa17 & Sperm autoantigenic protein 17 \\
\hline 1418893_at & BC010287.1 & Pbx2 & Pre B-cell leukemia transcription factor 2 \\
\hline 1417225_at & NM_022992.1 & Arl6ip5 & ADP-ribosylation-like factor 6 interactingprotein 5 \\
\hline \multicolumn{4}{|c|}{ Named genes expressed significantly lower after $A \beta$ treatment } \\
\hline 1449451_at & NM_025867.1 & Serpinb11 & Serine (or cysteine) peptidase inhibitor, clade B (ovalbumin), member 11 \\
\hline 1422168_a_at & NM_007540.1 & Bdnf & Brain derived neurotrophic factor \\
\hline 1417065_at & NM_007913.1 & Egr1 & Early growth response 1 \\
\hline 1451870_a_at & AF461396.1 & Brd4 & Bromodomain-containing protein BRD4 shortvariant \\
\hline 1421416_at & NM_011944.1 & Map2k7 & Mitogen activated protein kinase kinase 7 \\
\hline 1417416_at & NM_010595.1 & Kcna1 & Potassium voltage-gated channel, shaker-related subfamily, member 1 \\
\hline 1449904_at & NM_026700.1 & Dopey2 & Dopey family member 2 \\
\hline 1416039_x_at & NM_010516.1 & Cyr61 & Cysteine rich protein 61 \\
\hline 1415834_at & NM_026268.1 & Dusp6 & Dual specificity phosphatase 6 \\
\hline 1451828_a_at & AB033886.1 & mACS4 variant1 & Acyl-CoA synthetase 4 variant 1 \\
\hline 1422703_at & NM_008194.1 & Gyk & Glycerol kinase \\
\hline 1420800_a_at & NM_010611.1 & Kenq2 & Potassium voltage-gated channel, subfamily $Q$, member 2 \\
\hline 1449816_at & NM_020564.1 & Sult-x1 & Sulfotransferase-related protein SULT-X1 \\
\hline 1422931_at & NM_008037.1 & Fos 12 & Fos-like antigen 2 \\
\hline 1417466_at & NM_133736.1 & Rgs5 & Regulator of G-protein signaling 5 \\
\hline 1421598_at & NM_008834.1 & Phxr3 & Per-hexamer repeat gene 3 \\
\hline 1420696_at & NM_013657.1 & Sema3c & Sema domain, immunoglobulin domain (Ig), shortbasic domain, secreted, (semaphorin) $3 C$ \\
\hline 1422256_at & NM_009217.1 & Smstr2 & Somatostatin receptor 2 \\
\hline 1422831_at & NM_010181.1 & Fbn2 & Fibrillin 2 \\
\hline 1421306_a_at & NM_024124.1 & Mitr & Myocyte enhancer factor 2-interacting transcription repressor \\
\hline 1417871_at & NM_010476.1 & Hsd17b7 & Hydroxysteroid $(17-\beta)$ dehydrogenase 7 \\
\hline 1420342_at & NM_010268.1 & Gdap10 & Ganglioside-induced differentiation-associated protein 10 \\
\hline 1421170_a_at & NM_019677.1 & Plcb1 & Phospholipase $\mathrm{C}, \beta$ \\
\hline 1419681_a_at & NM_015768.1 & Prok1 & Prokineticin 1 \\
\hline 1450336_at & NM_010940.1 & Nscen1 & Nonselective cation channel 1 \\
\hline 1422868_s_at & NM_010266.1 & Gda & Guanine deaminase \\
\hline 1449945_at & NM_133249.1 & Ppargc1b & Peroxisome proliferative activated receptor $\gamma$, coactivator $1 \beta$ \\
\hline 1421738_at & NM_008066.1 & Gabra2 & $\mathrm{GABA}_{\mathrm{A}}$ receptor, subunit $\alpha 2$ \\
\hline 1449999_a_at & NM_009784.1 & Cacna2d1 & Calcium channel voltage-dependent, $\alpha 2 \delta$ subunit 1 \\
\hline 1421786_at & NM_024459.1 & Ppp3r1 & Protein phosphatase 3 , regulatory subunit $\mathrm{B}, \alpha$ isoform (calcineurin $\mathrm{B}$, type I) \\
\hline 1449895_at & M85170.1 & Acrosin & Acrosin \\
\hline 1418025_at & NM_011498.1 & Bhlhb2 & Basic helix-loop-helix domain containing, class B2 \\
\hline 1421199_at & NM_011807.1 & Dlgh2 & Chapsyn-110 \\
\hline 1420912_at & NM_033565.1 & Laf4l & Lymphoid nuclear protein related to AF4-like \\
\hline 1419765_at & NM_029402.1 & Cul2 & Cullin 2 \\
\hline 1418136_at & NM_009365.1 & Tgfb1i1 & Transforming growth factor $\beta 1$ induced transcript 1 \\
\hline 1424659_at & AF144628.1 & Slit2 & SLIT2 \\
\hline 1450288_at & NM_007666.1 & Cdh6 & Cadherin 6 \\
\hline 1420383_a_at & NM_023420.1 & Col4a3bp & Collagen, type IV, $\alpha 3$ (Good pasture antigen)-binding protein \\
\hline 1422823_at & NM_007945.1 & Eps8 & Epidermal growth factor receptor pathway substrate 8 \\
\hline 1450193_at & NM_010408.1 & $H c n 1$ & Hyperpolarization-activated, cyclic nucleotide-gated K + 1 \\
\hline 1419392_at & NM_011995.2 & Pclo & Piccolo (presynaptic cytomatrix protein) \\
\hline
\end{tabular}


Table 1. Continued

\begin{tabular}{|c|c|c|c|}
\hline Probe set & GenBank accession number & Symbol & Gene name \\
\hline 1451791_at & AF004833.1 & TFPI & Tissue factor pathway inhibitor \\
\hline 1448860_at & NM_080726.1 & $\operatorname{Rem} 2$ & Rad and gem related GTP binding protein 2 \\
\hline 1421340_at & NM_008580.1 & Map3k5 & Mitogen activated protein kinase kinase kinase 5 \\
\hline 1422785_at & NM_053268.1 & Rasa2 & RAS p21 protein activator 2 \\
\hline 1417010_at & NM_013915.1 & Zfp238 & Zinc finger protein 238 \\
\hline 1418589_a_at & AF100171.1 & Mlf1 & Myelodysplasiamyeloid leukemia factor 1 \\
\hline 1417110_at & NM_008548.1 & Man1a & Mannosidase $1, \alpha$ \\
\hline 1424800_at & D10727.1 & $n d p p-1$ & NDPP-1 protein \\
\hline 1448765_at & NM_008054.1 & Fyn & Fyn proto-oncogene \\
\hline 1418018_at & NM_007754.1 & Cpd & Carboxypeptidase D \\
\hline 1450656_at & NM_010303.1 & Gna13 & Guanine nucleotide binding protein, $\alpha 13$ \\
\hline 1426208_x_at & AF147785.1 & Zac1 & Zinc finger protein ZAC1 \\
\hline 1425202_a_at & U89274.1 & Ank3 & Ankyrin-3 \\
\hline 1450038_s_at & NM_009481.1 & Usp9x & Ubiquitin specific protease $9, \mathrm{X}$ chromosome \\
\hline 1421970_a_at & NM_013540.1 & Gria2 & Glutamate receptor, ionotropic, AMPA2 ( $\alpha 2)$ \\
\hline 1424986_s_at & AF391192.1 & Fbxw6 & F-box-WD40 repeat protein 6 \\
\hline 1450659_at & NM_011880.1 & Rgs7 & Regulator of G-protein signaling 7 \\
\hline 1448396_at & NM_018872.1 & Tmem131 & Transmembrane protein 131 \\
\hline 1417901_a_at & NM_010492.1 & lcal & Islet cell autoantigen 1,69 kDa \\
\hline 1417403_at & AF480860.1 & Masr & Myelination associated SUR4-like protein \\
\hline 1448736_a_at & NM_013556.1 & Hprt & Hypoxanthine guanine phosphoribosyl transferase \\
\hline 1416636_at & NM_053075.1 & Rheb & Ras-homolog enriched in brain \\
\hline 1450634_at & NM_007508.1 & Atp6v1a1 & ATPase, $\mathrm{H}^{+}$transporting, lysosomal $70 \mathrm{kDa}, \mathrm{V} 1$ subunit $\mathrm{A}$, isoform 1 \\
\hline 1419047_at & NM_018814.1 & Pcnx & cDNA sequence AF096286 \\
\hline
\end{tabular}

Summary of named genes that are differentially expressed in A $\beta$-treated cultures. Microarray analysis was performed on total RNA extracted from E13.5 cultures after $17 \mathrm{~h}$ treatment with $\mathrm{A} \beta$ compared and untreated cultures.

Tbr-1 mRNA (Fig. $2 A$ ) and protein (Fig. 2 E). At this age, only the cells destined for the deeper cortical layers (V and VI) are found in their final location between the marginal zone and subplate; the cells destined for the upper layers (II to IV) are still in the process of migration in the intermediate zone or completing the final cell divisions of the neurogenic process in the ventricular zone. Three days later [postnatal day $0(\mathrm{P} 0)$ ], the cortical plate has increased in depth and is populated by the maturing neurons of all six cortical layers. At this age, Tbr-1-postive cells continue to be present, but their location is restricted to the deeper layers, consistent with the interpretation that the protein is an effective marker of neurons in layers V and VI (Fig. 2B,F). Tbr-1 continues to mark cells of the deeper layers into adulthood (data not shown).

The nuclear receptor $\operatorname{ROR} \beta$ is reportedly found in layer IV, albeit with a rostral-to-caudal gradient of expression (Nakagawa and O'Leary, 2003). We were unable to secure an antibody that was applicable to mouse tissue and, thus, we restricted our analysis to in situ hybridization. At E16 (Fig. 2C) and P0 (Fig. 2D), a distinct layer of $\operatorname{ROR} \beta$ cells was detectable just below the marginal zone in the case of P0. This corresponds to the location of the future layer IV cells. Thus, as with Tbr- $1, \operatorname{ROR} \beta$ consistently marks the nerve cells of a distinct layer.

We used these markers to assess the representation of the various neuronal cell types in our dissociated cortical cultures. E13.5 neurons were neurons grown in Neurobasal medium for $5 \mathrm{~d}$. At the age of harvest (E13.5), the cells from layers VI and V are just finishing their final cell divisions in the ventricular zone. The upper layers are not yet generated as their progenitors are still in active mitosis. If there were no changes, therefore, plating of the cells derived from the dissociation of the entire cortical anlage should lead to a population of cultured cells that were fated to the deeper, but not the upper layers. When cultures were stained with Tbr-1, a significant number of $\mathrm{TuJ} 1^{+}$nerve cells also expressed Tbr-1 (Fig. 3C). In situ hybridization for the Tbr-1 message pro- duced a similar picture (Fig. $3 A$, green arrows). When identical cultures were stained for the presence of $\operatorname{ROR} \beta$ message, virtually none of the neurons expressed detectable levels (Fig. $3 B$, red arrows). Small cells of unknown identity were strongly positive for most messages tested; these cells were observed in all cultures (Fig. 3A-D, black arrows) and are not considered further here. Thus, despite the fact that $5 \mathrm{~d}$ had passed since the plating of the cells, making them the equivalent of E18.5 in cellular age, there is no suggestion that any upper layer neurons (as assessed by ROR $\beta$ expression) developed in our cultures.

We repeated these experiments using cortical cells harvested from E16.5 embryos. At this age in vivo, Tbr- $1^{+}$cells are well represented in the cortical plate although few if any $\operatorname{ROR} \beta^{+}$cells are present. Dissociated cells were plated under identical conditions to those used for the E13.5 experiments. When a probe for $\operatorname{ROR} \beta$ message is applied, a significant number of neuron-like cells in the cultures express high levels of the mRNA (Fig. 3E, green arrows). This result illustrates that layer IV cells can and do survive and differentiate in our E16.5 cultures. Further, visualized with either in situ hybridization for the Tbr-1 message or immunocytochemistry for the protein, the E16.5 cultures contained few Tbr-1-positive cells (Fig. 3D, red arrows, F, white arrows). The findings shown in Figure 2, $A$ and $B$, illustrate that these cells were present at the time of harvest. Their absence from our cultures suggests that they were lost either during the dissociation process itself or during the 5 culture days before our analysis. Thus, at both E13.5 and E16.5, the most prominent representatives found in dissociated cultures are cells that were in the ventricular zone just finishing cell division at the time of harvest. BrdU incorporation experiments validated these data (data not shown).

\section{Differential effects of $A \boldsymbol{\beta}$ toxicity}

Cultured mouse cortical neurons are frequently used in studies of human Alzheimer's disease because they are killed by exposure to 
oligomeric and/or fibrillar forms of the $\mathrm{A} \beta$ peptide. The peptide is the major constituent of the neuritic plaques, a pathological hallmark of the disease. In this way, $A \beta$ peptides are used to mimic the pathology of the AD brain. Dissociated cultures were established from embryos ranging in age from E13.5 to E17.5. After growth in serum-free media for $5 \mathrm{~d}$, the cultures were treated with $0,0.3,1,3,10$, and $30 \mu \mathrm{M}$ $\mathrm{A} \beta_{1-42}$. The cultures were then assayed for survival after $72 \mathrm{~h}$. Counts for all experiments were averaged and death was calculated as a percentage of untreated cells. The results of this experiment are shown in Figure 4. Neurons established from older embryos (E15.5 to E17.5) show the familiar response of rapid degeneration during the time period examined. In contrast, neurons established from E13.5 brains (open circles) were mostly resistant to $\mathrm{A} \beta_{1-42}$ toxicity. Neurons harvested from E14.5 brains showed intermediate survival.

These differences suggest that the underlying biology of the cells of the different layers is substantially different with regard to their response to the $\mathrm{AD}$-like conditions in our cultures. To ensure that the younger cells were capable of responding to the presence of $\mathrm{A} \beta_{1-42}$, E13.5 cultures were exposed to $A \beta$ for 5 or $10 \mathrm{~min}$ and wholecell protein lysates were prepared and run on denaturing SDS gels. The separated proteins were then probed with an antibody against phosphorylated tyrosine, a post-translational modification that occurs on several proteins shortly after exposure of cells to the $\mathrm{A} \beta$ peptide. Analyzed either as a whole, or in specific molecular weight regions, these results revealed that the cells could respond to the addition of $\mathrm{A} \beta$ to the cultures (data not shown).

\section{Expression array analysis of the effects of $A \boldsymbol{\beta}$}

In preparation for a larger study, we have performed an expression array analysis of the response of the E13.5 cultures at 0, 5, and $17 \mathrm{~h}$ after $\mathrm{A} \beta$ exposure. All measurements were made in triplicate. The overall response of these cultures was similar in nature to those seen in the phosphotyrosine blots. The microarray chip used was the Affymetrix Genechip Mouse Genome 430 2.0 Array of 45,000 probe sets representing 39,000 transcripts and variants of over 34,000 genes. Of this total, the levels of over 1000 of the E13.5 transcripts responded to the presence of $\mathrm{A} \beta$ with changes of twofold or more in the levels of message. Most of these changes were in the direction of decreased expression, but 45 transcripts, including 22 that code for known genes, increase their expression by twofold or more (Table 1). Of these, 10 increased more than fivefold after $17 \mathrm{~h}$. Thus, the cells are clearly responsive to the $\mathrm{A} \beta$ peptide, yet are not found to proceed to death after exposure. Also of note is that in comparing untreated cultures from E13.5 and E16.5 cultures, we found 132 transcripts, 26 of which code for known proteins that differ in expression levels between the two ages (Table 2). Of these, seven named genes were higher at E13 relative to E16, whereas 19 were lower.

\section{Differential survival of specific populations after A $\boldsymbol{\beta}$ treatment}

We also asked whether the differential survival might be the result of the hardiness of a specific population of cells that is more prevalent at a given age. To address this question, we focused on the population of Tbr- 1 cells (specific for layers V and VI) after $\mathrm{A} \beta$ treatment. Cultures were grown for $5 \mathrm{~d}$ in vitro followed by treatment with 10 or $30 \mu \mathrm{MA} \beta_{1-42}$ for a period of $72 \mathrm{~h}$. After treatment, both the E13 (Fig. $5 A, C$ ) and E16 cortical cultures (Fig. $5 B, D$ ) were fixed and labeled with Tbr-1 and TuJ1 antibodies. The percentage of double-positive cells ( Tbr $1^{+} / \mathrm{Tuj} 1^{+}$) was significantly higher in the E13 cultures than in the E16 cultures (Fig. $5 E$ ). Furthermore, this population of cells showed far greater resistance to the effects of $\mathrm{A} \beta$ in both the $\mathrm{E} 13$ (Fig. $5 E$, red bars) and E16 cultures (Fig. 5E, blue bars). This constancy of Tbr- $1^{+}$ cells was apparent despite the fact that total cell loss remained high in the E16 cultures after a $72 \mathrm{~h} \mathrm{~A} \beta$ treatment (Fig. $5 F$ ). As a consequence, the percentage of Tbr-1-positive cells increased from 14 to $\sim 42 \%$ of total cells. One issue raised by these cultures is that there are still Tbr- ${ }^{+}$cells in the E16 culture. We believe that this is attributable to the fact that we harvest cells from the entire cerebral cortex. Because there is considerable variation from region to region, the Tbr- $1^{+}$cells we find in our E16 cultures may well have come from the less-advanced regions. Indeed, even within a single region, there is variation in the final location of cells born at a given time. At E16, some progenitors are still fated for deeper layers as predicted by a population analysis of birth order, although the majority are fated for upper layers (Takahashi et al., 1995). What our data indicate, however, is that cells that are Tbr-1 positive, regardless of which day they were harvested, are resistant to the deleterious effects of $\mathrm{A} \beta$. 

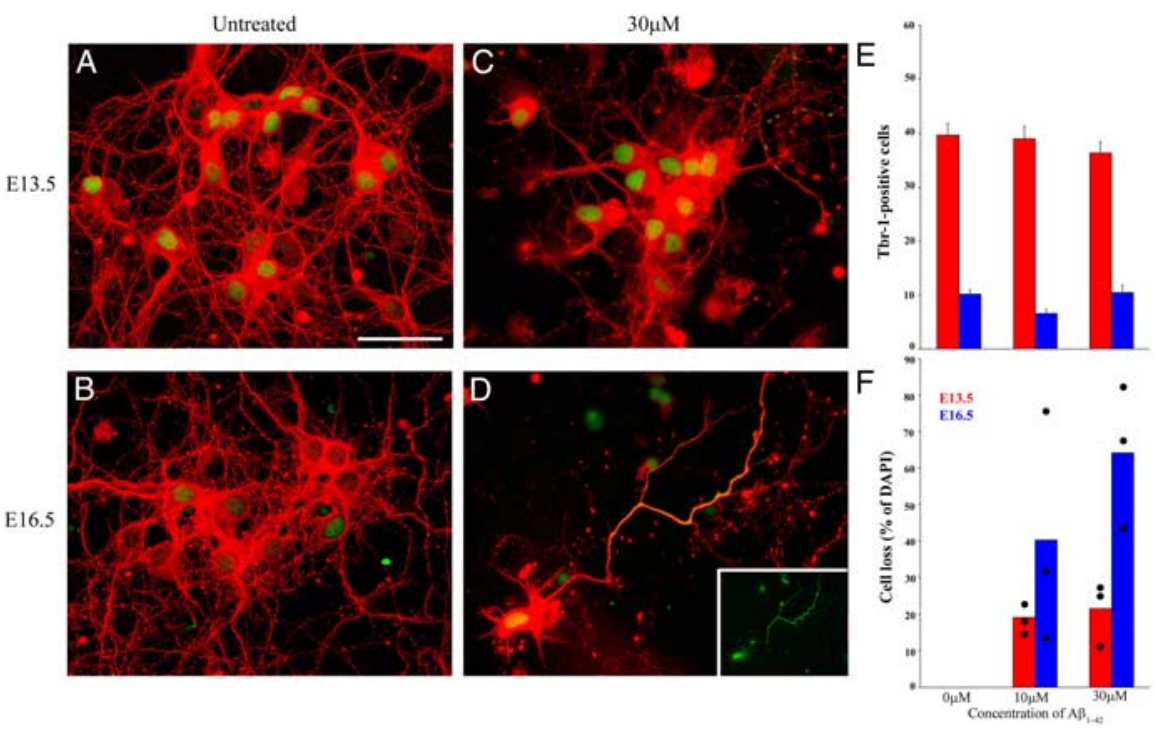

Figure 5. Differential cell survival of Tbr-1-positive populations after $A \beta$ treatment. $\boldsymbol{A}, \boldsymbol{B}$, Levels of Tbr-1 expression are illustrated in both E13.5 (A) and E16.5 (B) untreated cortical cultures. Cultures were stained with TuJ1 (red) and Tbr-1 (green). Replicate cultures were treated with 0,10 , and $30 \mu \mathrm{m} \mathrm{A} \beta_{1-42}$ for a period of $72 \mathrm{~h}$ followed by staining and counts of doublepositive cells. C, D, Tbr-1-positive cells persist even in the $30 \mu \mathrm{M}$-treated E13.5 (C) and E16.5 (D) cultures. Also, Tbr-1 expression appears to be more robust and extend into the neurites in many positive E16.5 treated cells ( $\boldsymbol{D}$, inset). In both E13 and E16 cultures, Tbr-1-positive populations appear to be resistant to $A \beta$ toxicity resulting in stable Tbr-1 numbers in the E13 and E16 cultures ( $\boldsymbol{E}$; error bars represent $\mathrm{SE}$ ) after a $>60 \%$ cell loss in the E16 cultures $(\boldsymbol{F})$. $\boldsymbol{F}$, Within any one replicate, the absolute number of surviving cells was variable, but the pattern was the same so values were expressed as percentages and shown as the mean of three experiments. Individual experimental means are displayed as dots. Scale bar: (in $\boldsymbol{A}) \boldsymbol{A}-\boldsymbol{D}, 50 \mu \mathrm{m}$.

We cannot ascribe these differences to neurons differentially generated by mitotic activity during the culture itself. The Neurobasal medium we use is not conducive to neuronal cell cycling. Indeed, when BrdU is added to cultures from the moment of plating and the cells are stained with BrdU antibody after 5 DIV, only a tiny fraction $(<5 \%)$ of TuJ1-postive cells are labeled with BrdU. Further, when cultures harvested on different days are examined, the levels of these double-positive cells do not differ significantly (R. Wang and K. Herrup, unpublished observations).

In addition, we observed an increase in the level of Tbr-1 expression as well as a change in localization in a subset of the surviving E16 cultured neurons. Tbr-1 expression, which is normally localized in the nucleus, can be seen extending out into the neurites of some surviving E16 neurons (Fig. 5D, inset). This may be indicative of cells that will eventually die or this may be a protective response. In contrast, in the E13 cultures, the percentage of Tbr-1-positive cells remained approximately the same after treatment. Our findings indicate that there is differential survival of specific neuronal populations after $\mathrm{A} \beta$ treatment and it may be the expression of specific proteins (or their absence) in those neurons that allows for their survival. One possibility is that Tbr- 1 itself may play a role in this resistance to $A \beta$ toxicity. The increased level of expression as well as the change in localization of this protein, particularly in isolated surviving E16 neurons, can be viewed as supporting its importance in cell survival after $\mathrm{A} \beta$ treatment.

\section{Discussion}

Each case of $\mathrm{AD}$ is probably unique in its emergence, but in the aggregate, there is a clear progression of the pathology during the course of the disease. This can be seen in the spread of the plaques and tangles from early to later disease stages. Plaques start primarily in superficial layers of cortex and progress to deeper layers as the disease advances. Once an area becomes heavily involved, however, plaques can be found in both superficial and deep layers. In less affected areas such as primary visual cortex, plaques tend to stay in the more superficial layers, even at advanced disease stages. The situation with the neurofibrillary tangles is equally nuanced. In visual cortex and other sensory areas with minimal pathology, tangles are primarily confined to the superficial layers. In contrast, in areas with more significant pathology, such as parietal, temporal, and prefrontal association cortices, the tangles are found in both layers III and V, becoming more numerous as the disease progresses. The more superficial layers tend to be involved in corticocortical connections whereas the deeper layers tend to project outside of cortex. Based on this, it would be reasonable to hypothesize that the differential vulnerabilities of the different regions and strata of the $\mathrm{AD}$ brain are a function of the connections rather than a reflection of deeper intrinsic vulnerabilities of the different neurons. To test this, we have used age of harvest as a way of manipulating the composition of dissociated cell cultures.

The demonstration that these layerspecific harvest protocols are successful can be seen both in the survival of BrdUlabeled neurons and in the preservation of certain layers specific markers. Exposure to BrdU will label only those cells that are actively synthesizing DNA during the exposure (a period of approximately $2 \mathrm{~h}$ after injection in vivo). Neurons that have completed the neurogenic process before this will be unlabeled; those that continue to divide will dilute the label by half during each subsequent mitosis. As expected, cultures established from either E15.5 or E13.5 embryos whose dams had been injected with BrdU $2 \mathrm{~h}$ before being killed (E15 ${ }^{+2}$ and $\mathrm{E} 13^{+2}$, respectively) contained a larger percentage of heavily labeled neurons when compared with the E15.5 embryos harvested from dams injected $2 \mathrm{~d}$ previously on E13.5 (E13/15). If embryonic cortices from E13/15 litters are fixed and sectioned instead of dissociated and plated, heavily BrdU-labeled cells are present, but they are located predominantly in the intermediate zone and deep layers of cortical plate. Only lightly labeled cells remain present in the ventricular and subventricular zones. The virtual absence of heavily labeled neurons in our E13/15 cultures suggests that these neurons are lost during the culture process. Given this pattern of behavior, our findings suggest that neuronal populations from many different brain regions respond similarly to the stresses of dissociation and culture. As already mentioned, Banker and Cowan (1977) have shown this for hippocampal neurons. Raetzman and Siegel (1999) reported nearly identical behavior for developing rat cerebellar granule cell neurons. Our findings extend these parallels to the neurons of the neocortex.

The persistence of the layer specific markers after $5 \mathrm{~d}$ in culture suggest that there are many features of the identities of the neurons that are retained in the dish. This suggestion is further strengthened by our observations of functional differences among the cells. One view of this situation is afforded by the expression array study. Comparing untreated cultures established on E13 with sister cultures established from E16, we de- 
tected 132 genes that differ in expression level between the two ages. Of these, 75 were higher at E13 relative to E16 whereas 57 were decreased. The functional differences were further revealed by the responses of the cells harvested on different days to a challenge with the $A \beta$ toxic peptide derived from the amyloid precursor protein. After $5 \mathrm{~h}$, there were a total of 489 genes that differed between the two ages; at $17 \mathrm{~h}$, this number had increased to 874 . The nature of the responding elements will be the subject of a subsequent analysis. For the present, the differential response to the $A \beta$ peptide underscores the strong dissimilarities in the biological composition of the two culture populations.

In Alzheimer's neuropathological studies, layers II and III are reported to be more heavily involved with $\mathrm{AD}$ pathological features than the deeper layers (Pearson et al., 1985; Lippa et al., 1992; Gomez-Isla et al., 1996). If the results from the human brain were viewed alone, it would be uncertain whether the layer heterogeneity were intrinsic to the neurons themselves or was instead imposed on them by the differential pattern of afferents and efferents to each layer. In our in vitro model, the neurons in the deeper cortical layers are intrinsically more resistant to the toxic influence of $\mathrm{A} \beta_{1-42}$, even as dissociated single cells, than are the association neurons of the more superficial layers. Thus, the in vitro model suggests that there are at least some neuronintrinsic factors that are likely to be at play in determining the pattern of neurodegeneration seen in the human $\mathrm{AD}$ brain.

Execution of the cell-death pathway in a neuron is a complex undertaking with many levels of control. Harvesting cortical neurons at E16 (a typical age, used by many laboratories) leads to the isolation of a group of neurons that are sensitive to the addition of fibrillar $\mathrm{A} \beta$ in the low micromolar range. In contrast, nerve cells plated from dissociates of E13.5 embryonic cortex are largely resistant to the same $A \beta$ treatment. This observation is in most ways a reflection of the differences found in the microarray analysis, yet the implications for the Alzheimer's disease brain are much more direct. Most laboratories harvest their cells at or around E16.5, but many do not. Some harvest at earlier dates such as E14-E15 (Lesne et al., 2005) or pool samples to include ages that our results suggest may have a different sensitivity to $\mathrm{A} \beta$, such as E14-E18 (Camacho et al., 2004; WasilewskaSampaio et al., 2005). Caution is necessary in comparing results across different labs when different ages of harvest are used to prepare neocortical cell cultures. It may be as important to document the layer identity of the neurons in a cortical culture as it is to distinguish neurons from non-neuronal cells. As only one example of this issue, our findings clearly illustrate that layer VI (Tbr-1 positive) neurons are resistant to the toxic effects of $A \beta$, even in cultures in which neurons from other layers are present.

\section{References}

Anderson S, Mione M, Yun K, Rubenstein JL (1999) Differential origins of neocortical projection and local circuit neurons: role of Dlx genes in neocortical interneuronogenesis. Cereb Cortex 9:646-654.
Banker GA, Cowan WM (1977) Rat hippocampal neurons in dispersed cell culture. Brain Res 126:397-425.

Bulfone A, Smiga SM, Shimamura K, Peterson A, Puelles L, Rubenstein JL (1995) T-brain-1: a homolog of Brachyury whose expression defines molecularly distinct domains within the cerebral cortex. Neuron 15:63-78.

Camacho IE, Serneels L, Spittaels K, Merchiers P, Dominguez D, De Strooper B (2004) Peroxisome-proliferator-activated receptor gamma induces a clearance mechanism for the amyloid-beta peptide. J Neurosci 24:10908-10917.

Cicero S, Herrup K (2005) Cyclin-dependent kinase 5 is essential for neuronal cell cycle arrest and differentiation. J Neurosci 25:9658-9668.

Combs CK, Bates P, Karlo JC, Landreth GE (2001) Regulation of betaamyloid stimulated proinflammatory responses by peroxisome proliferator-activated receptor alpha. Neurochem Int 39:449-457.

Gomez-Isla T, Price JL, McKeel Jr DW, Morris JC, Growdon JH, Hyman BT (1996) Profound loss of layer II entorhinal cortex neurons occurs in very mild Alzheimer's disease. J Neurosci 16:4491-4500.

Hyman BT, Van Hoesen GW, Damasio AR, Barnes CL (1984) Alzheimer's disease: cell-specific pathology isolates the hippocampal formation. Science 225:1168-1170.

Lavdas AA, Grigoriou M, Pachnis V, Parnavelas JG (1999) The medial ganglionic eminence gives rise to a population of early neurons in the developing cerebral cortex. J Neurosci 19:7881-7888.

Lesne S, Gabriel C, Nelson DA, White E, Mackenzie ET, Vivien D, Buisson A (2005) Akt-dependent expression of NAIP-1 protects neurons against amyloid-beta toxicity. J Biol Chem 280:24941-24947.

Lippa C, Hamos J, Pulaski-Salo D (1992) Alzheimer's disease and aging: effects on perforant pathway perikarya and synapses. Neurobiol Aging 13:405-411.

Nakagawa Y, O’Leary DD (2003) Dynamic patterned expression of orphan nuclear receptor genes RORalpha and RORbeta in developing mouse forebrain. Dev Neurosci 25:234-244.

Pearson RC, Esiri MM, Hiorns RW, Wilcock GK, Powell TP (1985) Anatomical correlates of the distribution of the pathological changes in the neocortex in Alzheimer disease. Proc Natl Acad Sci USA 82:4531-4534.

Raetzman LT, Siegel RE (1999) Immature granule neurons from cerebella of different ages exhibit distinct developmental potentials. J Neurobiol 38:559-570.

Rubenstein JL, Anderson S, Shi L, Miyashita-Lin E, Bulfone A, Hevner R (1999) Genetic control of cortical regionalization and connectivity. Cereb Cortex 9:524-532.

Takahashi T, Nowakowski RS, Caviness Jr VS (1993) Cell cycle parameters and patterns of nuclear movement in the neocortical proliferative zone of the fetal mouse. J Neurosci 13:820-833.

Takahashi T, Nowakowski RS, Caviness Jr VS (1995) The cell cycle of the pseudostratified ventricular epithelium of the embryonic murine cerebral wall. J Neurosci 15:6046-6057.

Takahashi T, Goto T, Miyama S, Nowakowski RS, Caviness Jr VS (1999) Sequence of neuron origin and neocortical laminar fate: relation to cell cycle of origin in the developing murine cerebral wall. J Neurosci 19:10357-10371.

Wasilewska-Sampaio AP, Silveira MS, Holub O, Goecking R, Gomes FC, Neto VM, Linden R, Ferreira ST, De Felice FG (2005) Neuritogenesis and neuronal differentiation promoted by 2,4-dinitrophenol, a novel anti-amyloidogenic compound. Faseb J 19:1627-1636. 